\title{
ONTOLOGÍA Y FÍSICA EN LA FILOSOFÍA DE SPINOZA: UN NUEVO MARCO COSMOLÓGICO \\ PARA LA NATURA NATURATA
}

\section{ONTOLOGY AND PHYSICS IN THE PHILOSOPHY OF SPINOZA: A NEW COSMOLOGICAL FRAMEWORK FOR THE NATURA NATURATA}

\author{
DANIEl ÁlVArez MONTERo* \\ Facultad de Filosofía \\ Universidad de La Laguna
}

RESUMEN: En este artículo mostraré la adecuación de los postulados fundamentales del marco ontológico spinozista para su integración en los avances de la física contemporánea en el ámbito de la cosmología -relatividad general y mecánica cuántica-. La fusión entre la ontología spinozista y la física actual enriquecería bilateralmente ambos discursos, de tal suerte que, cada uno, puede ampliar sus horizontes en la medida en que sus enunciados traspasarían su formulación original y alcanzarían, del lado del spinozismo, una exégesis física de su ontología y, para la física, un revestimiento teórico que acerque sus postulados al desarrollo de un proyecto ético-político.

Palabras Clave: Spinoza, física, ontología, relatividad, mecánica cuántica.

АвSTRACт: In this article, I will show the adaptation of the fundamental postulates of the Spinozistic ontological framework in order to integrate it into the new cosmological physics - general relativity and quantum mechanics. The fusion between Spinozistic

*Dr. en Filosofía por la Universidad de La Laguna. E-mail: astral.alv@gmail.com. 
ontology and present-day physics would enrich both discourses bilaterally, so that each can expand its horizons to the extent to which its statements could overstep their original formulation and reach, on the Spinozistic side, a physical exegesis of their ontology and, for physics, a theoretical frame that would bring its postulates closer to the development of an ethical-political project.

KEYwORDs: Spinoza, physics, ontology, relativity, quantum mechanics

\section{Introducción}

No es decir mucho constatar que la imagen física del cosmos en el siglo XVII es significativamente distinta de la presente; sin embargo, la filosofía spinozista supuso una disonancia en su contexto no ya por su oposición al dualismo y su reivindicación de una mens sobre la hasta entonces fuertemente establecida anima, sino también, y tal vez por accidente o sin consciencia de su verdadero alcance subversivo, por romper el esquema clásico de algunos conceptos físicos fundamentales. Es un tópico de la filosofía de la ciencia que la hegemonía de los conceptos de espacio, tiempo y materia, considerados como absolutos, no cambió de Aristóteles a Newton, ni desde éste a Einstein, y ello es cierto, al menos en líneas generales. No obstante, sí que alguien se apartó con su modelo ontológico de estas arraigadas asunciones; alguien que, por cierto, no trabajó al margen de su contexto científico. ${ }^{1}$

Absolutos, decía, en la medida en que aquellos titánicos conceptos parecían principios fundamentales de la Realidad -mayúscula-, o sus garantes para cualquier formación de un mundo. Condiciones a priori de la sensibilidad, diría Kant respecto del espacio y el tiempo, poco más de un siglo después. En efecto, ni la filosofía ni la física han contravenido una idea general básica: que estos dos conceptos -incluyo, también, la materia-, son notas genéricas de la Realidad -de nuevo, en mayúscula-; o, al menos, de nuestra Realidad. Sin embargo, la prudencia spinozista, consciente o no, convirtió a estos antaño absolutos en rasgos fundamentales de lo que llamó Naturaleza naturada, una concepción al margen de la Naturante. Así fueron definidas ambas en la Ética:

\footnotetext{
${ }^{1}$ Bien es conocida la habilidad y el trabajo del célebre pulidor de lentes en química y óptica, donde incluso se le atribuyen ciertos trabajos -aún en duda de su autoría, pero con fuertes evidencias de propiedad-: el Cálculo algebraico del arco iris y el Cálculo de probabilidades.
} 
Antes de seguir adelante, quiero explicar aquí -o más bien advertir- qué debe entenderse por Naturaleza naturante, y qué por Naturaleza naturada. [...] por Naturaleza naturante debemos entender lo que es en sí y se concibe por sí, o sea, los atributos de la substancia que expresan una esencia eterna e infinita, esto es, [...], Dios, en cuanto considerado como causa libre. Por Naturaleza naturada, en cambio, entiendo todo aquello que se sigue de la necesidad de la naturaleza de Dios, o sea, de cada uno de los atributos de Dios, esto es, todos los modos de los atributos de Dios, en cuanto considerados como cosas que son en Dios, y que sin Dios no pueden ser ni concebirse (E, I, 29, esc.). ${ }^{2}$

Naturaleza naturante, pues, cuando se está hablando de la Sustancia o sus atributos, de Dios ${ }^{3}$ en cuanto absoluta potencia generativa, indeterminada, infinita, eterna, atemporal, necesaria y libre. Naturaleza naturada, en tanto manifestación concreta o concretable, determinada o determinable, de esa potencia generativa. Es aquí donde recaen los conceptos anteriormente citados, como determinaciones de la Naturaleza -determinaciones concretadas en la forma de nuestra Naturaleza naturada-, concreciones que no agotan a Dios, que es el ser absolutamente infinito y no puede ser determinado de ninguna manera, pues ello le restaría potencia - determinatio est negatio-. De ahora en adelante centraré el discurso en la Natura naturata, expresión determinada de nuestro universo.

No obstante, antes de desarrollar la ulterior exposición, es preciso hacer una breve aclaración acerca del propósito de las siguientes líneas, a fin de no confundir la intención real de este texto. En un sentido que se comprenderá enseguida, comentaba Michel Paty, y creo que con razón, la necesidad de la prudencia a la hora de intentar unificar la ontología spinozista con la física actual, señalando incluso algunos intentos muy dudosos, cuando no sencillamente imposibles, orientados en este sentido (Paty, 1986). El error fundamental radica, en mi opinión, en la idea de unificación: no se trata de unificar dos universos de significados de contextos radicalmente diferentes intentando hacer pasar por una suerte de reunión atemporal mística una imagen del universo; no, se trata de

\footnotetext{
2 Para las citas a la Ética, sigo la traducción de Vidal Peña en su edición para Alianza editorial (ver bibliografía final).

${ }^{3}$ Asumo la comparativa spinozista Deus sive Natura y, en este trabajo, se utilizarán intercambiablemente los términos "Dios" y "Naturaleza" -esta última mayúscula cuando sea referida a la Sustancia-. Aparecerá "naturaleza" en minúscula cuando ésta sea referida a nuestro universo.
} 
reconstituir una filosofía del XVII desde el actual marco científico, a fin de anclar aquel proyecto ético de Spinoza -si ello fuera posible- en el presente modelo cosmológico -y, en última instancia, en una ontología del presente-. Contra la labor de una búsqueda extraordinaria de concordancias entre momentos históricos separados por varios siglos, lo que se propone en la brevedad de estas páginas es mostrar la viabilidad de alzar aquella Ética de Spinoza en el presente contexto científico, a sabiendas de que ello supone, obligatoriamente, otorgar un nuevo carácter a ciertos episodios, momentos o conceptos fundamentales del autor hispanoportugués; carácter que pretenderá, no obstante, mantenerse fiel y evitar la subversión de cualquier postulado fundamental de esta filosofía.

\section{Principios fundamentales de la digresión física spinozista}

Jacob Adler afirmó, en un artículo acerca de la filosofía física en Spinoza (Adler, 2001), que existían en la Ética una serie de enunciados que transgredían los límites de la pura ontología -y apartaban a un lado el discurso ético-, esbozando una imagen somera, aunque suficiente, de la expresión física del universo. No es una observación irrelevante, y tampoco la primera inquisición acerca de un modelo físico derivado de la metafísica spinozista que le fue formulada a su autor, pues ya en su Correspondencia se haya una carta de Tschirnhaus dirigida a Spinoza que empezaba de la siguiente forma:

¿Cuándo conseguiremos su método de dirigir rectamente la razón para adquirir el conocimiento de las verdades desconocidas, así como sus nociones generales de física? Tengo noticias de que usted hace tiempo que ha realizado en esto grandes progresos. Lo primero ya lo sabía y lo segundo se desprende de los lemas añadidos a la segunda parte de la Ética, con los cuales se resuelven fácilmente muchas dificultades de la física (Ep. 59). ${ }^{4}$

Es a estos lemas adonde dirigía su atención Adler en aquel breve trabajo, y los que conviene despertar de su letargo para las siguientes páginas.

\footnotetext{
${ }^{4}$ Sigo la traducción de Atilano Domínguez para la Correspondencia publicada en Alianza editorial (ver bibliografía final).
} 
Los primeros de ellos apuntarán en un sentido: constatar, para la materia organizada en forma de cuerpos, pues se hablará exclusivamente de la extensión-, que ésta se mueve o se halla en reposo, u oscila entre estos estados -bien sea moviéndose más rápido o más lentamente-. En el lema número 3 encontramos una curiosa -curiosa en la medida en que ha sido ignorada como tal-expresión de lo que luego será la primera ley de la dinámica newtoniana. Es cierto que ésta es una idea general de inercia que ya aparecía desde Kepler y Galileo, y que sólo con Newton alcanzará su precisa matematización y se integrará en lo que hoy conocemos como mecánica clásica, pero si bien la historia recuerda y honra la memoria de estos primeros teóricos, no puede decirse que haya pasado lo mismo con Spinoza, cuya figura ha sido ignorada por la gran mayoría de historiografía de la ciencia, algo no muy de extrañar cuando la propia obra del hispanoportugués fue filosóficamente repudiada por su comunidad y revalorizada en la contemporaneidad como una nota disonante en una época en la que no puedo brillar en su totalidad.

Digresiones historiográficas aparte, encontramos, pues, los mencionados enunciados, que dotan de un revestimiento físico a una obra que, a priori, podría parecer estrictamente ética-ontológica: "Un cuerpo en movimiento o en reposo ha debido ser determinado al movimiento o al reposo por otro cuerpo, el cual ha sido también determinado al movimiento o al reposo por otro, y éste a su vez por otro y así hasta el infinito" (E, II, lema 3). Y, también: "Se sigue de aqui que un cuerpo en movimiento se mueve hasta que otro cuerpo lo determina al reposo; y, asimismo, que un cuerpo en reposo permanece en él hasta que otro lo determina al movimiento" (E, II, lema 3, cor.). Y, dicho esto, además de otros enunciados generales cuya reproducción aquí extendería demasiado estas líneas, Spinoza afirma que ello se predica de: "los cuerpos más simples, a saber, los que sólo se distinguen entre sí por el movimiento y el reposo, la rapidez y la lentitud" (E, II, Ax. 2a).

Esta noción de cuerpos más simples 5 será recuperada más adelante, primero es preciso dedicar unas líneas al otro género de cuerpos: los compuestos.

Cuando ciertos cuerpos, de igual o distinta magnitud, son compelidos por los demás cuerpos de tal modo que se aplican unos contra otros, o bien — si es que se mueven con igual o distinto grado de velocidad — de modo tal que se comuniquen unos a otros sus movimientos según una cierta relación,

\footnotetext{
${ }^{5}$ Son llamados corpora simplicissima en la Ética.
} 
diremos que esos cuerpos están unidos entre sí y que todos juntos componen un solo cuerpo, o sea, un individuo que se distingue de los demás por medio de dicha unión de cuerpos (E, II, def.).

Éstos se ven afectados - podemos entender- por las mismas leyes que aquéllas que se aplican a los cuerpos más simples, pero los compuestos no sólo se distinguen entre sí por sus relaciones de movimiento y reposo, sino en virtud de su composición. Éste es un punto fundamental en lo que será el posterior esquema de la extensión de la Naturaleza naturada. Por lo pronto, es preciso hacer mención a la estructura de nuestro mundo en la medida en que es considerado compuesto, atendiendo al séptimo lema de esta segunda parte:

Por lo dicho, vemos, pues, cómo un individuo compuesto puede ser afectado de muchas maneras, conservando, no obstante, su naturaleza. Y hasta ahora hemos concebido un individuo que no se compone sino de cuerpos que sólo se distinguen entre sí por el movimiento y el reposo, la rapidez y la lentitud, esto es, que se compone de los cuerpos más simples. Si ahora concebimos otro, compuesto de varios individuos de distinta naturaleza, hallaremos que puede ser afectado de muchas otras maneras, conservando, no obstante, su naturaleza (E, II, Lema 7, esc.).

Y, de manera extensiva para todo el universo:

Si concebimos, además, un tercer género de individuos, compuesto de individuos del segundo género, hallaremos que puede ser afectado de otras muchas maneras, sin cambio alguno en su forma. Y si continuamos así hasta el infinito, concebimos fácilmente que toda la naturaleza es un solo individuo, cuyas partes — esto es, todos los cuerpos — varían de infinitas maneras, sin cambio alguno del individuo total (E, II, Lema 7, esc.).

De lo que Spinoza habla aquí es de la estructura extensa de todo el universo que, desde aquellos cuerpos más simples, esto es, los no compuestos -la unidad mínima estructural de la extensión considerada en tanto materia-, se organiza en estructuras más y más complejas hasta constituir todo el universo físico. No 
se observa una ruptura o salto entre unos estados o formas, o no es explícita al menos en ningún punto. Quiere esto decir que no habría una suerte de separación entre, dígase, un ser humano y un planeta distante, en tanto que como unidades estructurales forman parte de un esquema global de la Naturaleza naturada. El vacío absoluto no es una posibilidad teórica ni para la física contemporánea ni para la filosofía de Spinoza, siendo el espacio y, por supuesto, aquellas relaciones de movimiento y reposo, parte estructural de la inextricable constitución del universo extenso (Espinosa, 2000). Estas ideas globales serán mucho más que una mera categorización de los cuerpos de la naturaleza, encierran los principios generales fundamentales de la misma, que se expresan en la forma de los modos infinitos de la extensión. Ellos serán el objetivo del siguiente epígrafe.

\section{Estructura general de la Naturaleza naturada}

La digresión física nos lleva hacia el esquema global del universo, reflejado en forma de la Naturaleza naturada. ${ }^{6}$ Por supuesto que el universo está compuesto por cuerpos que son finitos y limitados, pero Spinoza nos exhorta a considerar en su estructura la existencia de modos que son infinitos; infinitos por su acción omniabarcante dentro del esquema naturado, por su presencia inextricable en la concreción modal de su atributo, pero que son modos en la medida en que se constituyen como determinaciones de la Naturaleza naturante, han tomado una forma a partir de ella, y esa forma ocupa la imagen física de todo el universo, que permea a través de cada uno de sus modos finitos.

A partir de la observación empírica, científica, de la multitud de modos del universo, la razón puede progresar hacia el conocimiento de los enunciados generales que lo forman, y la filosofía spinozista nos anima a pensar que de esta manera incluso, intuitivamente bajo la forma del tercer género de conocimiento, podríamos alcanzar una perspectiva sub specie aeternitatis más allá de la finitud y la temporalidad. Para el presente objetivo no es necesario asumir tanto y no importa ese salto, pues mediante la experiencia, que en palabras del autor

\footnotetext{
${ }^{6}$ Identificaré, en este escrito, nuestro universo con la Naturaleza naturada spinozista, y por supuesto no con la naturante -lo que sería un error fatal en cuanto que contraviene la exégesis spinozista-. Toda determinación o concreción es ámbito de una naturaleza ya modalizada, naturada, y nuestro universo en este esquema sería el producto de esa acción naturante; acción que no tendría por qué ser una y concretarse, desde una perspectiva contemporánea, en una única Naturaleza naturada -esto es, en un único universo-.
} 
determina el objeto que investigamos, ${ }^{7}$ podemos abstraer estas formas generalísimas del universo, un entendimiento empírico que no necesita salir del segundo género de conocimiento -que podríamos delinear de forma laxa como causal o científico-, para que a través de las célebres nociones comunes $^{8}$ pueda llegarse a la organización estructural del mismo.

Spinoza se había separado de la interpretación cartesiana de la extensión, arguyendo que era insuficiente para derivar de ella todas sus propiedades. Aquel plenum de materia parecía incapaz de dar cuenta de sus manifestaciones, lo que le llevó a considerar que algo debería ser anterior al carácter corpuscular de la extensión para que ésta pudiera desplegarse en su dinamismo. Ese algo en Spinoza es un concepto de importancia central para la física -y, cómo no, la filosofía- de nuestros días: el espacio. Esta lucidez teórica -adúzcase al motivo que sea, bien el azar, bien la genialidad- es lo que permite recuperar el modelo filosófico de Spinoza para nuestros días, comprobando cómo su marco ontológico no sólo puede contener la imagen actual del cosmos, sino que ésta puede precisar todo aquello que una filosofía del XVII sólo pudo constatar de forma muy general, mediante esa suerte de epagogé a través de las citadas nociones comunes - de las nociones comunes de la física de nuestros días, en virtud del desarrollo de la ciencia, podemos decir que son más ricas y permiten perfilar de mejor forma ese esquema modal que enseguida esbozaré-.

Así, la extensión queda dividida en tres tipos de modos: los finitos -en los que permean, como ya fue señalado, las notas genéricas de la Naturaleza naturada-,

\footnotetext{
7 "Antes de entregarnos al conocimiento de las cosas singulares, habrá tiempo de exponer los susodichos auxilios, todos los cuales tienden a que sepamos usar nuestros sentidos y realizar los experimentos conforme a leyes seguras y con orden. Estos bastarán para determinar el objeto que investigamos, hasta llegar, finalmente, a deducir según qué leyes de las cosas eternas ese objeto fue hecho y a conocer su naturaleza intima" (TIE, 103).

${ }^{8}$ Percepciones de las cosas que serán adecuadas cuando su esencia o su causa próxima sean conocidas, un conocimiento que se revela seguro y adecuado toda vez que pueda emitirse una definición verdadera sobre el mismo (definición que, en la obra de Spinoza, no puede sino ser genética, en oposición a la definición por género y diferencia). Estas nociones suelen malentenderse y confundirse con una suerte de concepto de clase o propiedad común, pero ello no sería más que un artificio de la imaginación que agrupa imágenes similares para su comodidad, nunca una representación fiable de la realidad. Errol Harris, en su obra The Substance of Spinoza, escribía esta, a mi juicio, acertada descripción: "what is common to parts of all things as well as wholes are those features characteristic of the attribute under which they fall. For instance, ideas of the characteristics inherent in the nature of Extension as such provide us with the propositions of geometry, which are about characteristics common to all extended things, both parts and wholes, and are necessarily true" $(1995,60)$.
} 
y los dos modos infinitos. De estos dos modos, la faz de todo el universo - facies totius universi- es el que engloba a todo el conjunto de cuerpos de la Naturaleza naturada, organizado según la noción de individuo compuesto. ${ }^{9}$ Representa, pues, al conjunto de cuerpos del universo en tanto que estructura, una unidad dinámica que, pese al movimiento de sus elementos constituyentes, se mantiene siempre invariable. Este modo recibe el nombre de modo infinito mediato de la extensión, y es mediato porque, como fue comentado unas líneas atrás, a juicio de Spinoza la estructura del cosmos en tanto materia no parecía poder explicar todas las formas de expresión de la misma, y es mediado por el otro modo infinito, que es anterior a esta $f a z$ y que recibirá el adjetivo inmediato.

Se llega de esta manera al modo infinito inmediato de la extensión, que serán las relaciones de movimiento y reposo -motus et quies-. Este modo da cabida a cualesquiera elementos del cosmos que permiten, posibilitan y son el suelo de la expresión matérica ${ }^{10}$ del universo. En Spinoza, este modo fue leído de manera general como el espacio (Bennett, 1984; Joachim, 1901), pero un espacio que no hace referencia a una suerte de marco estático donde tienen lugar los hechos -dicho concepto, además, ha sido rechazado por la física contemporánea-, sino un espacio dinámico que alberga complejas relaciones entre expresiones físicas de nuestro universo que determinarán la posterior forma de la materia -si la hubiere-. No se trata, pues, de una ingenua idea de vacio, ${ }^{11}$ sino una manifestación con estatus ontológico en la que podrían incluirse, por ejemplo, la energía, la gravedad o el electromagnetismo, realidades físicas todas que median en la construcción del universo en tanto individuo compuesto de cuerpos matéricos, y que en tiempos de Spinoza no pudieron ser precisadas a este nivel. ${ }^{12}$

\footnotetext{
${ }^{9}$ Cf. supra.

${ }^{10}$ Utilizo matérico en vez de material para eliminar la profunda carga semántica y connotaciones de este último concepto, ya que aquí en todo momento por materia se hablará de la expresión física y corpórea del universo, en oposición a otras formas del mismo como la gravedad o el electromagnetismo.

${ }^{11}$ Por cierto que la física contemporánea no maneja un concepto de vacío metafísico absoluto; el vacío cuántico, por ejemplo, dista mucho de ser un vacío real. Respecto de Spinoza, el vacío tampoco es una posibilidad ya desde la formulación primaria de Dios. Luciano Espinosa afirmaba del mismo, precisamente acerca de un diálogo entre la filosofía del hispanoportugués y el célebre físico David Bohm, que: "Es sabido que no se trata del Dios personal y trascendente de la teología, sino de una afirmación del ser desde la inmanencia y la univocidad formal [...]; lo que unifica y homologa lo real como un todo, y además como un continuo sin vacio." (2000, 310).

${ }^{12}$ Errol Harris, por ejemplo, afirmaba lo siguiente respecto de este modo infinito: "It is the configuration of the whole that is the infinite mode, not the particular changes, which produce, and occur among, the finite modes. Motion-and-rest must be conceived as a single indivisible 'state'
} 
La digresión física de la que se hablaba al comienzo de este epígrafe puede verse cristalizada en la forma de estas dos notas generalísimas del universo: por un lado, los cuerpos compuestos son aquéllos que manifiestan la forma de la facies totius universi, en tanto estructura matérica organizada; por otro lado, esta materia compuesta está en última instancia formada por los corpora simplicissima, los elementos matéricos más simples, que sólo se distinguen unos entre otros por sus relaciones de movimiento y reposo. Estos cuerpos simplísimos padecen las fluctuaciones propias de su directa relación con el modo infinito mediato, fluctuaciones por supuesto presentes en la organización estructural de la materia en mayor grado de composición, pero, igual que sucede en la física contemporánea, el comportamiento ondulatorio de una partícula es notorio desde una perspectiva microscópica, puesto que comprender el carácter ondulatorio de un planeta -estructura material macroscópica- carece de relevancia a tales escalas, donde la longitud de onda asociada a tales masas hace imposible apreciar ese carácter. ${ }^{13}$

Este dibujo físico de la Natura naturata es el que permite saltar a la ciencia contemporánea y proyectar el modelo ontológico de la filosofía spinozista desde el marco de la física actual, con todas las implicaciones que ello conllevaría. De un lado, que la física precise el funcionamiento de la Natura naturata de un modo imposible para el contexto histórico de Spinoza; del otro, integrando un discurso eminentemente físico en un modelo meta-físico holista que deviene en un proyecto ético-político, acercando esta disciplina científica a una labor común que apunta al conocimiento de la Realidad -mayúscula-, a todos los niveles.

of the entire physical world, an all-inclusive energy system which at once involves a structure, a dynamic pattern, of matter and interchange" $(1995,26)$.

${ }^{13}$ Fue Louis-Victor de Broglie quien constató que toda la materia presenta características que pueden expresarse tanto de forma ondulatoria como corpuscular, estudio por el que recibió el premio Nobel de física en 1929. 
Tales implicaciones, en cualquier caso, no pueden ser trazadas en la brevedad de estas páginas, que se ceñirán en lo sucesivo a la validez del marco cosmológico spinozista para nuestros días.

\section{Micro y macrocosmos desde la perspectiva de los modos infinitos}

Los corpora simplicissima siguen siendo, en cualquier caso, cuerpos, manifestaciones matéricas, pero no es la materia lo que constituye el motus et quies, o modo infinito inmediato de la extensión. Se habló de energía, de electromagnetismo, tal vez de gravedad y, en cualquier caso, de cualesquiera otras manifestaciones de propiedades de nuestro universo al margen de su estructura corpuscular. Cierto es que, siendo fieles al modelo de Spinoza, y asumiéndolo tal y como es en la medida en que ningún imposible teórico obligue a modificarlo en sus postulados fundamentales, todas estas realidades deben ser parte de esas relaciones de movimiento y reposo que, como establecí en el epígrafe anterior, constituyen cualesquiera mecanismos del universo que impelan a la materia al dinamismo. Pero estas propiedades de nuestro universo, aun teniendo realidad ontológica, no son el suelo del modo infinito inmediato de la extensión, sino más bien producto, consecuencia de éste. Si la faz de todo el universo no es ninguno de sus cuerpos por separado, sino la estructura inherente a los mismos, pues ello es lo único que podría dar cuenta de manera unitaria y completa a su continuidad en tanto modo infinito, ${ }^{14}$ de características idénticas debe ser el modo infinito inmediato, por supuesto recogiendo su genuina composición. Hay que tener presente que en todo momento escribo acerca de la extensión ya naturada, esto es, los modos infinitos de la misma, no aquélla en cuanto atributo -eso sería un completo error-.

Es aquí donde la perspectiva de la ciencia contemporánea se muestra sorprendentemente familiar con el modelo de Spinoza; sorprendente, en la medida en que un modelo ontológico del siglo XVII pueda extrapolarse a una física cuántica

\footnotetext{
${ }^{14}$ En palabras de Mendel Sachs, quien considero que da una ejemplar explicación de esta idea: "This is a view which asserts the elementarity of relation, not as a set of secondary restraints on relata, but rather as a basic order that is primary to an understanding of the real, substantive universe. It is an order in terms of fundamental relations, in the sense of logically necessary connections, where no manifestation of the universe, be it man or elementary particle, is unconnected from the rest of the single closed system" $(1976,130)$.
} 
como la presente. ${ }^{15}$ De gran interés para este tema, y en especial para disipar la idea de que este coqueteo entre una ontología del XVII y una física del siglo XX pueda ser un mero contubernio irrealizable, conviene repasar nuevamente qué lugar ocupa el modo infinito inmediato de la extensión en el esquema general de la Naturaleza naturada, a fin de orientar con precisión su posterior ubicación y comprobar si es posible seguir manteniendo los postulados del modelo de Spinoza desde una perspectiva contemporánea.

El modo infinito inmediato es, tal y como queda explicitado tras la lectura de las cartas número 63 y 64 de su Correspondencia, aquello inmediatamente producido por Dios y no mediante alguna modificación infinita -los modos finitos, por ejemplo, son producidos por estas modificaciones infinitas, o modos infinitos, como los he venido llamando-. Así, son la primerísima determinación de la Sustancia, aquello que primeramente se deriva de Dios, se concreta de su forma, la primera producción de la Naturaleza en sentido naturante, deviniendo ya en concreción. La Sustancia spinozista, la Naturaleza naturante en nuestros términos, es absoluta e infinita indeterminación, en ella no cabe determinación alguna, pues contravendría su propia definición. ${ }^{16} \mathrm{El}$ motus et quies es aquello que se ha concretado para la Naturaleza naturada como primera acción derivada de esta infinita potencia - por esto el modo es infinito- y, aunque no podamos decir que es absolutamente indeterminado -evidentemente, algo sabemos de él en tanto que podemos teorizar y perfilar qué recae de su lado-, sí es altamente indeterminado -al menos- desde la perspectiva humana. No es de extrañar, por tanto, que sea la primera determinación de la Naturaleza, y que de manera velada medie en la estructura matérica de la misma.

Ahora existe una disciplina que estudia la estructura microscópica del universo y las relaciones que en ella se producen, asumiendo la naturaleza ondulatorio-

\footnotetext{
${ }^{15}$ No debería ser preciso añadir que, en este trabajo, lo que se está haciendo es una lectura moderna del spinozismo desde nuestro actual modelo científico y que, por supuesto, en ningún momento Spinoza pudo anticipar algo tan elaborado y fundado sobre principios físicos muy posteriores a su vida como la teoría cuántica de campos o las premisas de la relatividad general.

${ }_{16}$ Sobre esta indeterminación de la Sustancia y los problemas inherentes a ella, léanse los detallados análisis de Vidal Peña en su obra: El materialismo de Spinoza. También, en un esbozo más breve, véase del mismo autor: La razón siempre a salvo. Ambos trabajos están recogidos en la bibliografía final. Más concretamente en torno de la problemática para el tema presente, la posibilidad de orientar un discurso común entre filosofía y física, véase también el texto de Luciano Espinosa: Spinoza y David Bohm: un diálogo sobre filosofía natural, también referido en la bibliografía final.
} 
corpuscular de la materia anteriormente reseñada. Hablo de la mecánica cuántica, de la que tan sólo extraeré un principio fundamental de cara a la subsiguiente exégesis aplicada al modelo físico-ontológico del spinozismo: la indeterminación. Independientemente de las distintas interpretaciones de esta disciplina, e incluso de los debates acerca de si es una teoría física completa o no, su fundamento es la noción de indeterminación, una que no es producto de la carencia de instrumentos o conocimientos del observador, sino una propiedad indefectible de los sistemas cuánticos.

La indeterminación absoluta de la Sustancia no es la indeterminación de la que se habla en física, y tampoco debería serlo cuando se habla de aquella inherente al modo infinito inmediato de la extensión. Efectivamente, la indeterminación cuántica no es azarosa, ni mucho menos admite cualquier posibilidad -la indeterminación subyacente al modelo de Spinoza tampoco es producto del azar, sino de la causalidad-. Un evento cuántico dado podría determinarse de manera A o B, pero no Z. La propia configuración física de la Natura naturata es la que cierra y abre este marco de expansión ontológico, porque, si somos fieles al modelo de Spinoza, este modo infinito es ya una determinación, inabarcable por mor de su infinitud y de la que brota su espacio de indeterminación. Aquí puede encajar, de manera sobresaliente, la disciplina que encara las propiedades anteriores a los corpora simplicissima, aquellos cuerpos que sólo se diferenciaban entre sí por sus relaciones de movimiento y reposo; relaciones que, tanto en la física contemporánea como en la ontología de Spinoza, parecen ser en un sentido anteriores a la propia materia -0 , cuando menos, muestran que ésta no pueda darse sin aquélla-.

La infinitud contiene un tipo de indeterminación, que no es la indeterminación absoluta de la Sustancia o Dios, pero que se conjuga en la relación de lo humano con lo infinito, de la finitud con la infinitud, toda vez que una sea inabarcable desde la otra. Se trataría de una indeterminación fundada en la inabarcable relación de modos dentro de una Naturaleza naturada expansiva y en continuo devenir, no del tipo que podría aplicarse a la extensión en cuanto atributo, donde la noción apropiada sería la de potencia absoluta, posibilidad o virtualidad, y es anterior a la concreción modal de una Naturaleza ya determinada.

Es por esto que, tal vez desde una perspectiva contemporánea, sea adecuado llamar a los modos infinitos de la Naturaleza naturada ilimitados -los finitos, por supuesto, son susceptibles de ser llamados limitados-. En una identificación como la expuesta en este artículo, la Natura naturata equivale a nuestro universo, 
y no tendría por qué ser una representación global del todo de lo real. Si aceptamos esta exégesis, entonces sería más seguro clasificar los modos en ilimitados o limitados, más que en infinitos o en finitos - nuestro universo, en efecto, podría ser infinito, pero también podría no serlo, por lo que es más seguro desde una interpretación moderna del spinozismo modificar esta lectura-.

Por otro lado, la faz de todo el universo es, desde una perspectiva global, precisamente aquello que predica en su nombre: el cómputo de todo el carácter matérico del universo considerado en tanto estructura relacional, comprendiendo toda su forma. Cierto es, se dirá, que el macrocosmos, desde una perspectiva física, comprende más que la mera materia. La gravedad, por ejemplo, es determinante aquí y prácticamente irrelevante en el microcosmos. Esto no supone, en cualquier caso, ninguna traba a esta perspectiva, nunca se debe olvidar que la Natura naturata spinozista no funciona transitivamente ni evoluciona o se va generando mediante distintos estadios separados. Si sucediera de esta forma, un modo no mediaría en el otro, sino que uno se generaría a partir del otro, lo que es falso.

La simultaneidad y respectividad estructural de cada modo es la base del sistema: en la infinitud de los modos que he llamado ahora ilimitados se suceden, generan y aniquilan los modos finitos -o limitados-, en un panorama de dinamismo y mutabilidad continuo. No hay creación ni destrucción absoluta sino, siguiendo una suerte de ley de la termodinámica, transformación. Léanse las palabras de Spinoza al final de la cuarta carta de su Correspondencia:

[...] considere que los hombres no se crean, sino que únicamente se engendran y que sus cuerpos ya existían antes, aunque bajo otra forma. De aquí se sigue algo que yo acepto de buen grado: que, si se aniquilara una parte de la materia, se desvanecería simultáneamente toda la extensión (Ep. 4).

\section{Perspectiva global de la Natura naturata}

Hasta ahora no ha generado mayores complicaciones entender el esquema de la naturaleza spinozista desde una perspectiva contemporánea, representando la faz de todo el universo como, precisamente, el rostro macroscópico del universo, 
mediado continuamente por todas las propiedades que lo determinan y que he situado en el modo infinito inmediato. Energía, electromagnetismo, gravedad, interacciones nucleares fuertes y débiles, etcétera, son elementos clave mediadores en lo que será la organización de la estructura matérica del cosmos; estructura que, desde una perspectiva macroscópica, he situado en el modo infinito mediato. Lo que se ha hecho es, en esencia, incluir las ideas más generales de la cosmología contemporánea en el marco ontológico de Spinoza, a fin de que conceptos como facies totius universi o motus et quies representen más de lo que pudieron en su día, y legando a la física contemporánea la evolución de este estudio naturado de la extensión.

No obstante, el esquema spinozista está dividido en infinitos atributos, y como de ellos sólo dos nos son accesibles, al menos esos dos deberían estar contemplados en este marco global de la Naturaleza naturada. ¿Qué sucede con el atributo del pensamiento desde esta perspectiva cosmológica? Decir que el universo es matérico porque, efectivamente, en él se da la materia -ésta es una propiedad del mismo-, debería tener la misma validez que decir que es tempóreo o espacioso y, por supuesto, que el universo es pensante. Efectivamente, en el universo se da el pensamiento, como se da la materia, y de este modo ambos son propiedades, notas suyas. Aislar el pensamiento humano del resto de elementos del cosmos implicaría, desde la visión spinozista, separar al ser humano como Sustancia aparte, y eso está más que negado desde los mismos fundamentos del modelo: "No puede darse ni concebirse substancia alguna excepto Dios" (E, I, 14). Y: "A la esencia del hombre no pertenece el ser de la substancia, o sea, no es una substancia lo que constituye la forma del hombre" (E, II, 10).

De la misma manera que la materia es una expresión de la extensión, pero no la agota ni constituye toda su forma, sucede igual con el pensamiento humano: es una propiedad del universo, una característica del mismo tan real como la propia existencia pensante de cada sujeto, que, igual que sucede con la materia, no tiene por qué estar presente en todos los momentos del atributo del pensamiento, sino sólo donde así se haya organizado mediante aquel proceso de transformación. ¿Cuál es, entonces, el suelo de estas configuraciones personales del pensamiento? Spinoza le da nombre explícitamente: el intellectus absolute infinitus. Este modo infinito es el inmediato desde la consideración del universo en tanto pensamiento; esto es, es al pensamiento lo que el motus et quies a la extensión, es aquello que media en esas particularidades conscientes, que lo necesitan para poder ser tales. 
Argüir que el universo es pensante está muy lejos de creer que el universo es un único organismo autoconsciente que piensa en un sentido humano. Efectivamente, esto no se alejaría demasiado de una concepción de Dios en sentido teísta. Sin embargo, el universo piensa en cada una de sus manifestaciones autoconscientes -que conozcamos, los seres humanos-, pero ese pensar en Spinoza consiste en una existencia de ideas, y ésta es el modo infinito inmediato del pensamiento. Hay ideas de todo lo real en la medida en que todo lo real puede ser expresado bajo el atributo del pensamiento -del mismo modo en que todo puede ser expresado en forma de extensión, desde aquel atributo-. Puede decirse en este sentido que el universo tiene intelecciones, aunque éstas sean diferentes a las que posee un ser humano, en la medida en que el intellectus absolute infinitus supone una trabazón de ideas impersonal, ideas que no necesitan ser pensadas por nadie para ser reales, mera expresión del carácter pensante de la Sustancia. ${ }^{17}$

$\mathrm{Al}$ amparo de la anterior exposición, no sólo no hay problema en considerar al pensamiento como una nota más del universo, como un adjetivo o propiedad extra, sino que desde esta perspectiva incluso se da cabida a su realidad desde un mismo modelo que da cuenta a la vez de lo físico y lo mental, de cuerpo e idea, en un sistema monista que no separa la realidad ni la jerarquiza, sino que la integra en un mismo esquema. El atributo del pensamiento puede ser así interpretado, a mi juicio, sin menoscabo ni perjuicio alguno desde la nueva ciencia.

\section{Conclusiones}

La física contemporánea no sólo no es incompatible con el modelo ontológico del spinozismo, sino que puede ayudar a determinar y confirmar la existencia de una naturaleza continua y simultánea -esto es, no transitiva-. ${ }^{18}$ Las relaciones entre el micromundo y el macromundo, en la medida en que muestran una naturaleza compleja y, desde luego, aún desconocida, confirman esa interacción modal que aparecía en forma infinita en el esquema de la Naturaleza

\footnotetext{
${ }^{17} \mathrm{La}$ diferencia, pues, entre el modo infinito inmediato del pensamiento, que alude a un orden impersonal de ideas, y lo que sería el modo infinito mediato, que englobaría a las totalidades conscientes, radica precisamente en esto último: la recursividad de la idea o autoconsciencia. Este tema, que ha generado un extensísimo debate, se aleja mucho del objetivo de estas páginas.

18 "Dios es causa inmanente, pero no transitiva, de todas las cosas" (E, I, 18).
} 
naturada; pero no sólo la corroboran, sino que la amplían, precisándola tanto como la propia física ha podido, hasta la fecha, desvelar. Más aún, si la mecánica cuántica ha encontrado bajo el principio de indeterminación un posible límite del conocimiento, se habría a su vez reforzado el modelo de Spinoza que propone una Naturaleza naturante indeterminada, y esta indeterminación presente mediante otra máscara en la Naturaleza naturada, y que sí es alcanzable mediante la física, tal vez nos enfrente a ese metafórico paso desde la Naturaleza naturante hacia la naturada; paso que hasta ahora sólo era considerado como un abismo insalvable en su forma lógica.

A este respecto, Vidal Peña ha hecho algunos comentarios esclarecedores que secundan la idea de la imposibilidad lógica de mostrar el funcionamiento deductivo del tercer género de conocimiento, puesto que la deducción desde un infinito indeterminado a una concreción es imposible de manera lógica (2011, 167 ss). La física contemporánea, en un discurso aparte, muestra que la concreción desde la indeterminación hacia la determinación es una realidad física que escapa a la predicción y las leyes clásicas de causalidad -al menos, en el tipo de indeterminación relativo a la mecánica cuántica, que no es, por supuesto, del tipo que se aduce a la Sustancia spinozista o Naturaleza naturante-; esto es: escapa a esa deducción precisa que del mismo modo no podía atribuirse al tercer género de conocimiento. Tenemos, por ello, motivos en nuestros días para pensar que la indeterminación no es una barrera que invalida la derivación, aunque ésta esté condenada a sernos desconocida - del mismo modo en que Vidal Peña comentaba que el tercer género de conocimiento estaba señalado, pero no probado (2006, 165), así se revela que sólo mediante la observación de un evento cuántico obtenemos su resultado, y no de otra manera-. Sólo mediante lo mostrado -en física, de hecho, sólo mediante la observación podemos conocer cómo se ha resuelto dentro de sus posibilidades ese tal evento cuántico-, podemos constatar lo existente, del mismo modo en que en Spinoza la experiencia sirve "para determinar el objeto que investigamos" (TIE 103).

Incluso en la brevedad de estas líneas, creo que no es poco lo que ha sido expuesto: primero, que la física contemporánea no ha invalidado el modelo ontológico spinozista, en la medida en que sus postulados fundamentales pueden traducirse al marco general de aquélla; por otro lado, que la física contemporánea puede iluminar y precisar, de una forma que era imposible en tiempos de Spinoza, de qué manera la naturaleza interactúa entre sí en sus distintas formas. La misma empresa sugería Van Zandt a propósito de Spinoza en su texto Res extensa and the space-time continuum: "Perhaps the time is now ripe to suggest that physics 
and philosophy may, indeed, be able to cooperate in the quest to understand nature" $(1986,250)$. Mediante la posibilidad de organizar y reestructurar una visión del cosmos que deviene en lo humano en la realización de un proyecto ético, tal vez sea posible, como fue comentado en la introducción a este artículo, aunar un trabajo común, nuevo, entre física y filosofía, y no tratar de unificar dos elementos cuyos orígenes y sentidos han deambulado mayoritariamente desvinculados, fuente, en mi opinión, de la gran mayoría de inexactitudes e imposturas en torno a la conciliación de estas dos disciplinas.

\section{Bibliografía}

Adler, JaCob (2001). "Spinoza’s Physical Philosophy". Spinoza: Critical Assessments of Leading Philosophers (t. II). Londres: Routledge, pp. 165-189.

Bennett, Jonathan (1984). A Study of Spinoza's Ethics. Indianapolis: Hackett.

Domínguez, Atilano (1988). Correspondencia [tr.]. Madrid: Alianza.

- (2006). Tratado de la reforma del entendimiento. Principios de Filosofia de Descartes. Pensamientos metafísicos [tr.]. Madrid: Alianza.

Espinosa, Luciano (2000). "Spinoza y David Bohm: un diálogo sobre filosofía natural”. Estudios filosóficos Vol. 49/141, pp. 309-328.

Harris, Errol (1995). The Substance of Spinoza. Nueva Jersey: Humanities Press.

Joachim, Harold H. (1901). A Study of the Ethics of Spinoza. Londres: Oxford Clarendon Press.

Mendel, Sachs (1976). "Maimonides, Spinoza, and the Field Concept in Physics". Journal of the History of Ideas Vol. 37/1, pp. 125-131.

Paty, Michel (1986). "Einstein and Spinoza". Spinoza and the Sciences, Dordrecht: Kluwer, pp. 267-302.

Peña, Vidal (1974). El materialismo de Spinoza. Madrid: Revista de Occidente.

— (2006). Ética [tr.]. Madrid: Alianza.

- (2011). La razón siempre a salvo. Oviedo: KRK.

VAn ZANDT, Joe D. (1986). "Res extensa and the space-time continuum". Spinoza and the Sciences, Dordrecht: Kluwer, pp. 249-266. 
Enviado: 20/06/2016

Aceptado: 19/09/2016

\section{(9) 190}

ENDOXA está bajo una licencia de Creative Commons Reconocimiento-NoComercial-SinObraDerivada 4.0 Internacional 
